\title{
Heartbeat: empowering patients with digital home management
}

doi:10.1136/heartjnl-2020-318237

Catherine M Otto

Digital technology now offers unprecedented opportunity for patients to be actively involved in monitoring and managing their chronic cardiovascular conditions. Patients have access to lowcost devices that can monitor heart rate continuously, record an electrocardiogram, quantitate daily physical activity and measure blood oxygen saturation as well as body weight and home blood pressure measurements. However, we need to ensure that patient selfmonitoring is implemented in ways that improve quality of life and clinical outcomes.

In this issue of Heart, Rahimi and colleagues ${ }^{1}$ report a clinical trial of 202 high-risk patients with heart failure (HF) randomised to home self-monitoring of weight and blood pressure versus additional centralised specialist feedback to the patient about self-management and to the patient's primary provider about recommended blood tests and medical therapy. Interestingly, there was no difference between groups in use of guidelinerecommended medical therapy or in patient's physical well-being. In addition, there were no significant differences in cardiovascular events, hospital admissions or mortality (table 1 ).

These disappointing results lead us to ask, as queried in an editorial by Dardas and Dorsch, ${ }^{2}$ "What factors led to this negative finding and to the increasingly large body of work demonstrating little effect of mobile health (mHealth) technologies on patient outcomes?' Some issues they discuss include the challenges using a central clinical management team acting asynchronously outside the patient's normal care team; the inclusion of both patients with HF with preserved ejection fraction and $\mathrm{HF}$ with reduced ejection fraction (HFrEF) which might dilute any benefit in those with HFrEF; and the infrequent change in medications in the HFrEF patients. They note that 'The path between data acquisition and outcome reduction is elusive and must ultimately converge on timely delivery of treatment that

Correspondence to Professor Catherine M Otto, Division of Cardiology, University of Washington, Seattle, WA 98195, USA; cmotto@uw.edu

\begin{tabular}{|c|c|c|c|}
\hline Outcome & $\begin{array}{l}\text { Enhanced self- } \\
\text { management }(n=101)\end{array}$ & $\begin{array}{l}\text { Supported medical } \\
\text { management }(n=101)\end{array}$ & P value* \\
\hline \multicolumn{4}{|l|}{ All events } \\
\hline Death & $6(5.9 \%)$ & $13(12.8 \%)$ & 0.09 \\
\hline Hospital admissions & $29(28.7 \%)$ & $40(39.6 \%)$ & 0.13 \\
\hline \multicolumn{4}{|l|}{ Cardiovascular events } \\
\hline Cardiovascular death & $3(2.97 \%)$ & $2(1.98 \%)$ & 0.65 \\
\hline $\begin{array}{l}\text { Hospital admissions for cardiovascular or } \\
\text { renal outcomes }\end{array}$ & $13(12.9 \%)$ & $13(12.9 \%)$ & 1.00 \\
\hline
\end{tabular}

affects health and well-being.' In my view, we also need to involve patients more actively in the design, implementation and presentation of studies using home-based digital monitoring of chronic cardiovascular disease. Obviously, patient-centred care requires a central role for patients in research and implementation of new strategies to improve health.

The optimal approach to 'ruling out' an acute coronary syndrome (ACS) in the emergency department remains controversial. In a randomised controlled trial of 632 patients (mean age 54 years, $41 \%$

female) from eight hospitals in the UK, Carlton and colleagues ${ }^{3}$ found that with a strategy based on an undetectable highsensitivity cardiac troponin (hs-cTn) and non-ischaemic ECG (limit of detection and ECG discharge (LoDED)), 46\% were discharged within 4 hours, compared with $37 \%$ in the usual care group (figure 1). There was no difference in major adverse cardiac events at 30 days comparing the LoDED strategy to usual care (OR 1.50, $95 \%$ CI 0.76 to 3.02 ).

In an editorial, Lee and Mills ${ }^{4}$ point out that there have been few randomised controlled clinical trials

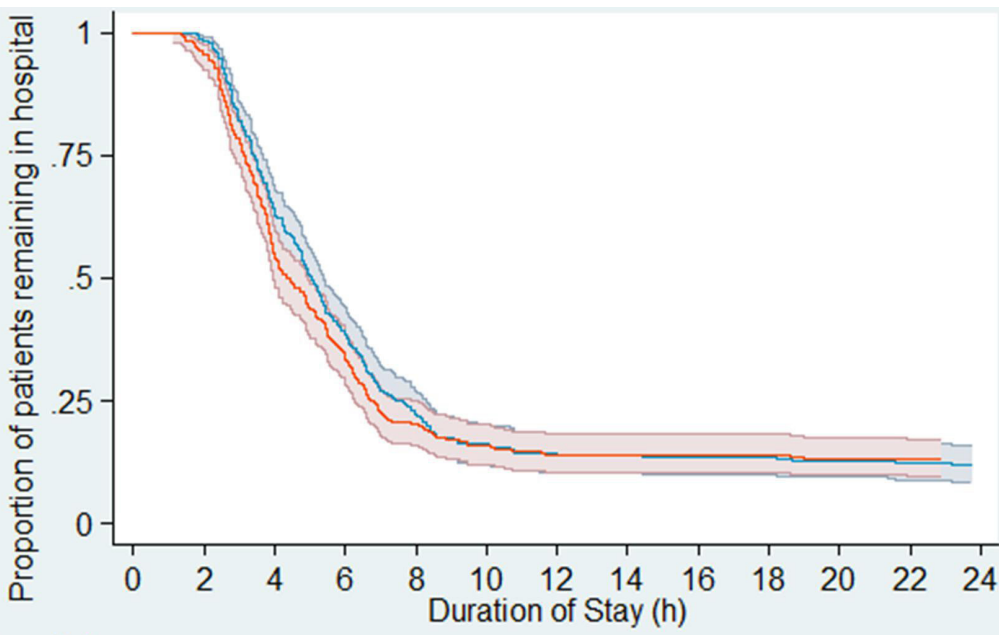

Number in hospital

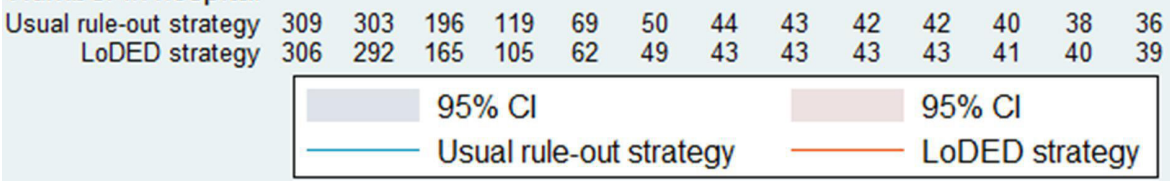

Figure 1 Kaplan-Meier-type length of stay curve by group allocation (intention to treat). LoDED, limit of detection and ECG discharge. 
Patient first presenting with features of constrictive pericarditis without an obvious underlying etiology

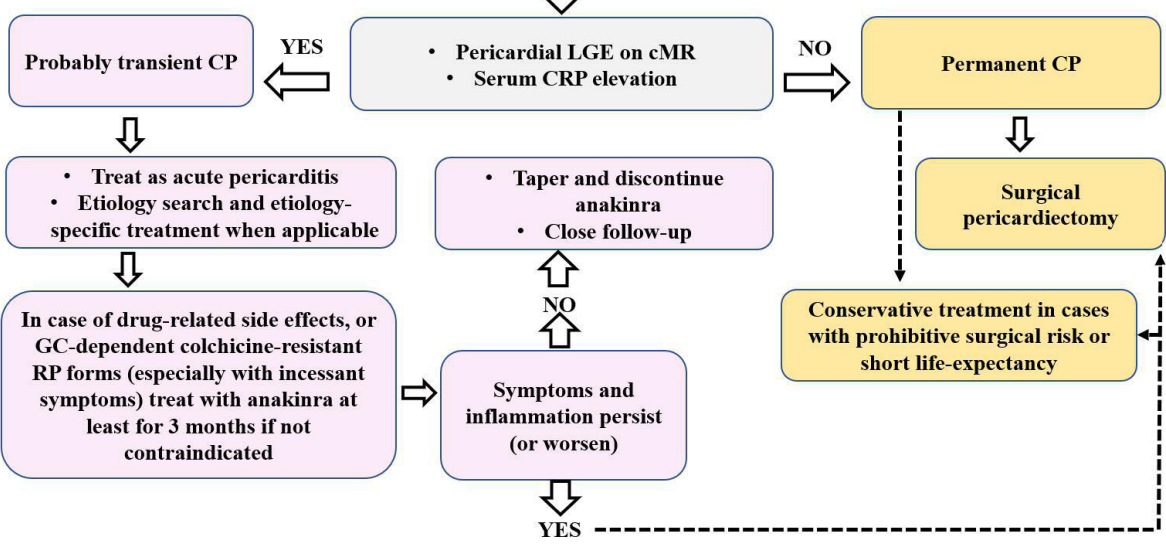

Figure 2 Proposed algorithm for the management of patients with constrictive pericarditis. cMR, cardiac magnetic resonance; $C P$, constrictive pericarditis; $C R P, C$ reactive protein; $G C$, glucocorticoid; LGE, late gadolinium enhancement; RP, recurrent pericarditis. evaluating the safety and efficacy of rule-out pathways based on a very low hs-cTn, even though this approach is widely used and is recommended in clinical guidelines. However, 'the LoDED trial did not demonstrate that using a high-sensitivity cardiac troponin concentration below the limit of detection at presentation was more effective than usual care to rule-out myocardial infarction in the emergency department.' Potential reasons why this trial did not demonstrate a meaningful difference in efficacy between usual care and the LoDED strategy include: (1) many of the participating hospitals were already using a limit of detection threshold for hs-cTn, (2) the study may be underpowered to detect a significant difference between strategies, (3) the trial population was relatively young and low-risk compared with unselected patients with suspected ACS and (4) a higher hs-cTn threshold may have

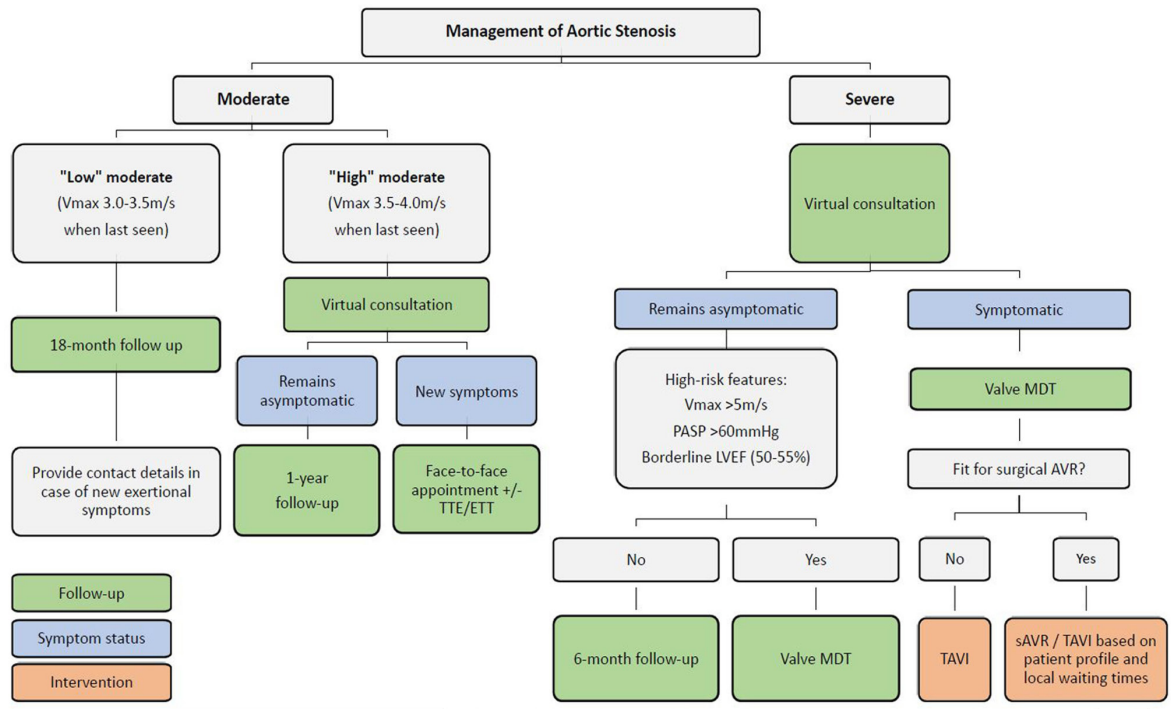

Figure 3 Flow diagram for proposed management of moderate and severe aortic stenosis following the COVID-19 pandemic. Certain patients with asymptomatic severe aortic stenosis but certain 'high risk' features should also be considered for intervention in the valve MDT meeting, but it is essential that symptomatic patients are treated before asymptomatic patients. AVR, aortic valve replacement; ETT, exercise treadmill test; LVEF, left ventricular ejection fraction; MDT, multidisciplinary team; PASP, pulmonary artery systolic pressure; SAVR, surgical aortic valve replacement; TAVI, transcatheter aortic valve implantation; TTE, transthoracic echocardiogram. greater efficacy with similar safety. 'Nevertheless, there were a number of encouraging insights which require further investigation. The LoDED trial and other randomised controlled trials addressing this topic are much needed to raise the quality of evidence used to inform national and international clinical practice guidelines.'

Although infrequently seen by most cardiologists, a particularly vexing clinical problem is incessant or recurrent pericarditis (RP) which can lead to constrictive pericarditis (CP). Andreis and colleagues ${ }^{5}$ hypothesised that treatment with anakinra, an interleukin-1 inhibitor, could treat CP due to incessant or RP and reduce the need for surgical pericardiectomy, which is associated with a high operative mortality and morbidity. In a study of 39 patients with recurrent or incessant pericarditis dependent on chronic glucocorticoids (GCs) and resistant to colchicine therapy, CP developed in $20 \%$ of patients, most often those with incessant pericarditis, and reversed with use of anakinra in 5 of these 8 patients $(63 \%)$.

This data is put into context by Lazaros and Tousoulis ${ }^{6}$ who remind us that although pericarditis accounts for up to about $50 \%$ of CP cases, other causes include post-cardiac surgery (11\%-37\%), irradiation therapy (9\%-31\%), connective tissue disorders (3\% to $7 \%$ ), tuberculosis or bacterial pericarditis $(3 \%-6 \%)$ and less common causes $(<10 \%)$ such as malignancy, trauma and uraemia. They point out that 'the study of Andreis et $a l^{5}$ is the first one that has systematically assessed the impact of anakinra administration in patients with GC-dependent colchicineresistant RP and clinical features of CP.' Additional remarkable findings are the unexpectedly high rate $(20 \%)$ of CP observed in patients with GC-dependent colchicine-resistant pericarditis and the extremely rapid progression of GC-dependent colchicine-resistant pericarditis. 'Taking into account the most recent ESC guidelines on pericardial syndromes, the updated experience on anakinra administration in pericardial diseases and the aforementioned paper results, we propose the algorithm depicted in figure 2 as a practical guide for the management of CP.'

As we continue to balance the care of our patients with cardiovascular disease against the sometimes-limited healthcare resources due to the COVID-19 pandemic, useful guidance is provided 
Table 2 Heart best research paper award winner and finalists 2020

\begin{tabular}{|c|c|c|}
\hline \multicolumn{3}{|l|}{ Winner } \\
\hline Ralph Kwame Akyea, Joe Kai, Nadeem Qureshi, Barbara lyen, Stephen FWeng & $\begin{array}{l}\text { Suboptimal cholesterol response to initiation of statins and } \\
\text { future risk of cardiovascular disease }\end{array}$ & $\begin{array}{l}\text { Heart Jul 2019, } 105 \text { (13) 975-981; DOI: } \\
\text { 10.1136/heartjnl-2018-314253 }\end{array}$ \\
\hline \multicolumn{3}{|l|}{ Finalists } \\
\hline $\begin{array}{l}\text { Weijian Huang, Lan Su, Shengjie Wu, Lei Xu, Fangyi Xiao, Xiaohong Zhou, Guangyun } \\
\text { Mao, Pugazhendhi Vijayaraman, Kenneth A Ellenbogen }\end{array}$ & $\begin{array}{l}\text { Long-term outcomes of His bundle pacing in patients with } \\
\text { heart failure with left bundle branch block }\end{array}$ & $\begin{array}{l}\text { Heart Jan 2019, } 105 \text { (2) 137-143; DOI: } \\
\text { 10.1136/heartjnl-2018-313415 }\end{array}$ \\
\hline $\begin{array}{l}\text { Ralph Maddison, Jonathan Charles Rawstorn, Ralph A H Stewart, Jocelyne Benatar, } \\
\text { Robyn Whittaker, Anna Rolleston, Yannan Jiang, Lan Gao, Marj Moodie, Ian Warren, } \\
\text { Andrew Meads, Nicholas Gant }\end{array}$ & $\begin{array}{l}\text { Effects and costs of real-time cardiac telerehabilitation: } \\
\text { randomised controlled non-inferiority trial }\end{array}$ & $\begin{array}{l}\text { Heart Jan 2019, } 105 \text { (2) 122-129; DOI: } \\
\text { 10.1136/heartjnl-2018-313189 }\end{array}$ \\
\hline
\end{tabular}

in a review article on management of patients with heart valve disease, particularly aortic stenosis (figure 3), following the pandemic ${ }^{7}$ and an Education in Heart article on management of patients with ACSs. ${ }^{8}$

Please also join me in congratulating the winner and finalists for the Heart Best Research Paper Award 2020 (table 2). ${ }^{9}$

Funding The authors have not declared a specific grant for this research from any funding agency in the public, commercial or not-for-profit sectors.

Competing interests None declared.

Patient and public involvement Patients and/ or the public were not involved in the design, or conduct, or reporting, or dissemination plans of this research.

Patient consent for publication Not required.
Provenance and peer review Not commissioned; internally peer reviewed.

C C Author(s) (or their employer(s)) 2020. No commercial re-use. See rights and permissions. Published by BMJ.

\section{D) Check for updates}

To cite Otto CM. Heart 2020;106:1537-1539.

Heart 2020;106:1537-1539.

doi:10.1136/heartjnl-2020-318237

\section{ORCID iD}

Catherine M Otto http://orcid.org/0000-0002-05279392

\section{REFERENCES}

1 Rahimi K, Nazarzadeh M, Pinho-Gomes A-C, et al. Home monitoring with technology-supported management in chronic heart failure: a randomised trial. Heart 2020;106:1573-8.
2 Dardas T, Dorsch MP. Remote management of heart failure: Herculean or Sisyphean task? Heart 2020;106:1543-4.

3 Carlton EW, Ingram J, Taylor H, et al. Limit of detection of troponin discharge strategy versus usual care: randomised controlled trial. Heart 2020;106:1586-94.

4 Lee KK, Mills NL. Early rule-out pathways for myocardial infarction: is observational data enough? Heart 2020;106:1545-6.

5 Andreis A, Imazio M, Giustetto C, et al. Anakinra for constrictive pericarditis associated with incessant or recurrent pericarditis. Heart 2020;106:1561-5.

6 Lazaros G, Tousoulis D. Interleukin-1 inhibition with anakinra: a valuable ally to reverse constrictive pericarditis? Heart 2020;106:1540-2.

7 Nijjer SS, Petraco R, Sen S. Optimal management of acute coronary syndromes in the era of COVID-19. Heart 2020;106:1609-16.

8 Shah BN, Schlosshan D, McConkey HZR, et al. Outpatient management of heart valve disease following the COVID-19 pandemic: implications for present and future care. Heart 2020;106:1549-54.

9 Otto CM. Heart Best Research Paper Award 2020. Heart 2020;106:1617-8. 